\title{
A CIDADE E SUAS RUÍNAS, PENSANDO AS AMBIÇÕES RACIONALISTAS DE NARRATIVAS VISUAIS
}

\author{
Ana Luiza Carvalho da Rocha \\ Rafael Victorino Devos \\ Alfredo Barros
}

A intenção que move este artigo é de apresentar o vídeo-pesquisa A cidade e suas ruínas como um espaço de "provocação" para se discutir as poéticas visuais que sustentam uma narrativa etnográfica sobre os significados dos gestos e atos de destruição da paisagem urbana no quotidiano dos habitantes da cidade.

O trabalho aqui apresentado se constitui numa tentativa de reunir as imagens captadas de sobrados antigos abandonados, os depoimentos de personagens sociais que habitam alguns destes casarios e as leituras da obra de Bachelard (1989) que compõem o Projeto Estudo antropológico de itinerários urbanos, memória coletiva e patrimônio etnológico no mundo contemporâneo ${ }^{1}$ num vídeo-documentário cujo principal objetivo é trazer à reflexão os modos de composição de narrativas audiovisuais sobre memória no campo das produções da Antropologia Visual.

Segundo Simmel (1934), se as ruínas abandonadas revelam uma "passividade positiva", "porque o homem se faz cúmplice da natureza, "permitindo a destruição" e "adotando uma maneira de agir que é oposta a sua verdadeira essência", as ruínas habitadas “tomam o aspecto problemático, inquieto, muitas vezes insuportável, de lugares onde a vida se retirou e que, sem dúvida, entretanto, aparecem como recintos e marcos de uma vida".É, assim, nas fronteiras entre a alma que aspira uma transcendência"e o pensamento que se dirige à captura do mundo que os jogos da memórias se configuram. Obra humana, as ruínas de uma cidade e os seus moradores ocasionais, verdadeiros guardiães da memória de tais lugares, como no caso de Andriana Bohrer Maciel.

\footnotetext{
${ }^{1}$ Projeto Integrado de Pesquisa, coordenado pela Profa. Dra. Cornelia Eckert do Núcleo de Estudos sobre Culturas Contemporâneas pertencente ao Laboratório de Antropologia Social, do PPG Antropologia Social/UFRGS.
} 
Enquanto parte integrante dos registros documentais recolhidos ao longo da pesquisa, em particular no corpo do sub-projeto "Banco de Imagens e efeitos visuais: coleções etnográficas, patrimônio etnológico e itinerários urbanos" , com a coordenação de Ana Luiza Carvalho da Rocha, a obra gerada reflete sobre as metamorfoses da intriga gerada pela figura de Kronos devorador no como parte da operação configurante das narrativas contemporâneas sobre a Crise no mundo urbano-industrial.

Da mesma forma, pertence ao campo de reflexão da obra produzida uma necessidade de ser refletir sobre a tradição literária do Ocidente $^{2}$ que impregna a narrativa etnográfica em Antropologia, em particular, no caso da Antropologia Visual, mesclada das influências do romance e do cinema.

\section{Alguns apontamentos finais}

Sob o plano da pesquisa, a realização do vídeo-documentário significou o amadurecimento de uma discussão entre a equipe de pesquisa nos termos de aproximar a controvérsia dos pós-modernos a respeito do realismo na narrativa etnográfica em Antropologia clássica e

A intenção que move este projeto é o estudo de possíveis técnicas de narrativas que auxiliem na estrutura de construção dos roteiros de pesquisa e documentários visuais que fazem parte do projeto que tem como tema de investigação o patrimônio etnológico do mundo urbano contemporâneo.

O estudo de métodos de pesquisas, não só instrumentalizadas pelas imagens (analógicas e digitais) como também utilizando-se das mesmas como fonte de reflexão e construção de conhecimentos em torno da memória e da Cidade, aliam-se, no vídeo-pesquisa realizado, ao esquadrinhamento dos recursos narrativos advindos do paradigma interpretativa

${ }^{2}$ Cf. P. Ricoeur, Tempo e Narrativa II, SP, Papirus, 1994 p.38 o mito do Apocalipse, nas tradições do Ocidente ultrapassa o domínio da ficção literária atingindo os domínios "teleológico, através da escatologia judaico-cristã, histórico-político, através da ideologia imperial viva até a queda do Santo Império romanogermânico, e epistemológica, através da toeira dos modelos... “ 
em Antropologia, e a ele ${ }^{3}$ soma-se as contribuições proporcionadas pela tradição literária e cinematográfica.

É partir dos estudos sobre Tempo e Narrativa (1994), na obra de P. Ricoeur, e os estudos sobre as estruturas antropológicas, em G. Durand (1984), aliados à prática de captação e manipulação das imagens que desenvolveu-se este experimento etnográfico narrativo que tanto busca combinar técnicas etnográficas clássicas quanto no sentido de gerar novas reflexões sobre tratamento formal de composição de documentário versando sobre a memória da cotidianidade no meio urbano de Porto Alegre.

Este trabalho de pesquisa a partir de notas visuais produzidas em campo se caracteriza por seu aspecto predominantemente laboratorial, com experiências de técnicas e procedimentos metodológicos em direção à construção de uma narrativa etnográfica visual para fins de registro documental do meio urbano.

\section{A cidade, a destruição criativa e o registro audiovisual}

Com o intuito de investigar as formas da vida social no meio urbano, o movimento dessas formas que, desenhadas no tempo, constituem um território urbano comum a seus habitantes- aqui entendido como princípio da "unidade estilística" da vida citadina local optou-se por integrar o vídeo como instrumento privilegiado de pesquisa.

Tendo como eixo condutor a concepção de pesquisa que elabora seu a partir das imagens em movimentos, o vídeo a ser apresentado expressa a intenção primeira de aprofundar experimentos etnográficos visuais na cidade dentro de uma abordagem simeliana dos fenômenos da vida social que ao centrar na exploração de narrativas que expressem a dimensão estético dos fenômenos culturais.

Trata-se, assim, de desenvolver novas propostas em etnografia experimental do mundo urbano contemporâneo, através do recursos de novas tecnologias comungam com questões cogitadas atualmente por alguns setores da antropologia que buscam, segundo

\footnotetext{
${ }^{3}$ Cf. Cardoso de Oliveira, R. A categorias de (des)ordem e a pós-modernidade da antropologia. Segundo o autor, o antropólogo classifica os "paradigmas racionalista,e estrutural-funcionalista e culturalista, orientadores respectivamente da École Française de Sociologia, da British School of Social Anthropology e da American Historical School of Anthropology". O quarto domínio dessa matriz disciplinar, segundo o autor, fica por conta do paradigma hermenêutico do qual fazem parte a Antropologia interpretativa, "dialógica", "crítica" e "pós-moderna". Cardoso de Oliveira acredita que a coexistência dessa nova antropologia com s tradicionais traz uma "uma tensão que pode ser estimuladora de novos experimentos".
} 
Marcus e Cushman (1991) ${ }^{4}$, submeter as convenções do gênero realista em Antropologia a diversas classes de experimentações.

O gênero realista, como lembram tais autores, utiliza-se do conjunto dessas convenções (como ponto de vista, argumento, estilo, etc.) para projetar a ilusão de totalidade do mundo retratado. Nessa tradução, os conflitos e ambigüidades próprios das relações em campo acabam por ser neutralizados. Assim, nas artimanhas arquitetadas no berço positivista, com a finalidade de garantir uma maior sensação de objetividade científica na escritura etnográfica, as formas de apreensão do mundo estudado e da obtenção de informações ficam, geralmente, ocultadas.

No trabalho com a imagem em movimento algumas estratégias acabam por ser inevitavelmente reveladas. Antes de tudo, ela afirma, com propriedade, a presença do pesquisador, sublinhando o "eu estive lá" tão caro à tradição da autoridade etnográfica.

Um experimento etnográfico visual pode expor (dependendo da construção narrativa pela qual opta o autor) a inter-relação e a tensão existente no jogo da alteridade do eu com o “outro", revelando o pesquisador "oculto” em suas próprias estratégias de apreensão e manipulação das imagens.

A "escritura"com a imagem em movimento - acrescida do som sincronizado que the é peculiar - transforma-se em possibilidade de construção de retratos etnográficos que a um só tempo desvendam as formas como estes encontros se tramam, as estratégias- intencionais ou casuais- de obtenção das informações e ainda revelar o exercício polifônico e heteroglótico no qual as relações sociais se estruturam.

Sublinhando a proposta polifônica de encontro etnográfico, J. Cliffod (1991) coloca “a etnografia não como uma experiência ou uma interpretação de "outra"realidade circunscrita, mas sim como uma negociação construtiva que envolve pelo menos a dois, e habitualmente a mais sujeitos conscientes e politicamente significantes". ${ }^{6}$

Nesse sentido, a produção recente dos cientistas sociais (ou ainda jornalistas, videomakers e cineastas) que produzem seus discursos utilizando-se das imagens em

\footnotetext{
${ }^{4}$ Cf. Marcus, E. G.e Cushman, E.D., Las etnografias como textos. in: Reynoso, C. (org) El surgimento de la antropologia posmoderna. Barcelona, Gedisa, 1991.

${ }^{5}$ A moderna autoridade do trabalho de campo, ou o "estás ali porque eu estive ali", cf. Clifford, J. in: Reynosos C. (org), El surgimento ...., op.cit.

${ }^{6}$ Cf. Clifford, J. Sobre la autoridad etnográfica. In: Reynoso, C. (org.), El surgimiento ... op.cit.
} 
movimento têm apresentado narrativas que endossam as propostas de novas escrituras etnográficas. $^{7}$

A opção metodológica do desenvolvimento desses experimentos etnográficos incorporando o processo de registro audiovisual ao trabalho de campo, implica um projeto, uma obra aberta que se constrói por etapas decorrentes do próprio percurso da investigação.

Concebida em diferentes momentos que ora se alternam, ora entrecruzam-se, tem como objetivo primeiro a construção de técnicas narrativas em etnografia visual no e do mundo urbano. É nas diferentes etnografias já realizadas em correntes antropológicas diversas, bem como nas fontes literárias e na diversidade das propostas narrativas cinematográficas que vai-se buscar a gênese de interpretações e o material para a elaboração de relatos visuais da Cidade.

O produto acabado de cada processo experimental, que envolve laboratório de pesquisa teórica, aliada a laboratórios práticos de captação, roteiro e montagem das imagens, chamar-se-á aqui de documentários etnográficos. Cada um dos documentários- pequenas narrativas - está pautado em uma ou mais linhas temáticas, conforme o acima exposto.

A fim de retratar, no documentário etnográfico, o comportamento estético dos personagens que habitam territórios-mitos da cidade de Porto Alegre, utiliza-se técnicas oriundas da antropologia urbana e da antropologia visual ${ }^{8}$ tanto quanto recursos estilísticos da linguagem cinematográfica e literária.

Produzida em duas etapas distintas que denominam-se, respectivamente, "pesquisa de etnografia visual" e "elaboração e realização de documentário etnográfico", o presente vídeos vêm comungar com procedimentos metodológicos advindos das áreas de conhecimento supra citadas.

\footnotetext{
${ }^{7}$ Conferir os trabalhos de Carelli, V. e Gallois, D. Asch, T., Macdougall, Goldenberg, S., entre tantos realizadores que produzem com a preocupação em traçar uma etnografia de culturas estrangeiras ou familiares a sua.

${ }^{8}$ Remeto a coletânea organizada por FRANCE, Claudine. "Pour une anthropologie visuelle". Paris, Cahiers de L'Homme, 1979, bem como a organizada por MENEZES, Cláudia (org.) Antropologia Visual. Caderno de Textos. Rio de Janeiro, Museu do Índio, 1987. O catálogo da II Mostra Internacional de Antropologia Visual, Rio de Janeiro, 1994, traz artigos recentes de dois importantes antropólogos visuais da atualidade, Marc Henri Piault e David Mc Dougall, textos esses fundamentais da reflexão epistemológica embasadora desta pesquisa. Além destes os escritos que explicitam a metodologia de Dziga Vertov encontrados em XAVIER, Ismail (org.). A experiência do cinema. Rio de Janeiro, Graal, 1983 e as concepções de Serguei EISENSTEIN, expressas em livros de sua autoria ("A forma do filme" e "A função do filme", ambos publicados pela Zahar, em 1990) são fundamentais no processo de reflexão da concepção de uma linguagem visual.
} 
Mesmo não sendo privilégio apenas dos cientistas sociais que trabalham com a imagem em movimento - já que se têm notícias de cineastas que se utilizam de tal abordagem -, o que aqui chamamos de "pesquisa de etnografia visual", na verdade caracteriza-se como uma fase exploratória de pesquisa de campo a respeito das feições da crise e do medo no mundo contemporâneo

O emprego de notas visuais de campo como instrumento de registro documental esta associado a preocupação de retratar estilisticamente a feição estética configuradora de uma cultura urbana, tornando-se, aqui no caso, uma etapa obrigatória deste projeto em suas preocupações com o fenômeno da memória coletiva que encerram as formas de vida social na Cidade.

\section{Algumas adoções e decisões metodológicas na pesquisa com imagens}

Ainda que motivados por procedimentos metodológicos e abordagens teóricas diversas, o vídeo-documentário encontra inspiração nos "antropólogos visuais" e na sua conduta "em campo". Ou seja, à práticas constante de levarem suas câmeras a campo, realizando entrevistas, captando imagens da maneira como as pessoas vivenciam suas relações com o tempo e o espaço numa dada cultura.

Tendo como suporte dos rituais de aproximação entre os informantes e o o antropólogo, o aparato tecnológico e o movimento/deslocamento da equipe em campo foi um aspecto essencialmente relevante na geração de indagações dos informantes ocasionais, habitantes da rua, interessados no sentido do registro de imagens de ruínas numa cidade voltada apenas recentemente ao tema do patrimônio artístico e histórico da cidade. Neste ponto, a realização do vídeo adota o pressupostos da construção de fazer antropológico dado a partir de um amálgama que inclui conceitos quotidianos empregados pelos habitantes/ moradores de grandes cidades e conceitos científicos, onde a captação de imagens une-se ao ato interpretativo tanto do antropólogo como dos eventuais informantes que possam se dispor a dar seu depoimento durante a captaçào das mesmas.

O período "pesquisa de etnografia visual” foi, antes de tudo, uma etapa laboratorial, onde não só revisitamos as narrativas advindas de diferentes tradições da antropologia, da literatura e do cinema, como também buscamos o desenvolvimento de outras a partir de combinações e experimentos elaborados na interface entre arte e ciência. 
Nessa etapa laboratorial seguiu-se um processo de escolha do assunto a ser abordado dentro da cidade de Porto Alegre, o estudo e a composição da técnica narrativa a ser adotada, o registro e, finalmente, a edição das imagens escolhidas. Os registros de imagens utilizados foram considerados antes como "anotações visuais", pois tinham a intenção de compreender o universo estudado: a cidade e as suas ruínas. ${ }^{9}$

Inevitável aqui alguns reflexões epistemológicas que integraram não só o trabalho da campo, mediado pelas 'notas visuais', mas as suas implicações na analise da composição narrativa que continham os registros das imagens segundo seu campo semântico particular.

Mais importante que anunciar o 'estar ali' do etnógrafo, tratamos de investigar as possibilidades e os limites de se representar, através da composição formal da narrativa, a expressão de uma estética coletiva que reúne indivíduos e grupos urbanos e o contexto da cidade em mutação.

Com a câmera no ombro no lugar de um bloco de anotações, tendo como preocupação central o nosso próprio processo de objetivação do conhecimento etnográfico, a equipe confrontou-se seguidamente com as suas experiências subjetivas em campo.

A câmera, nesse caso, foi concebida como um meio privilegiado na apreensão das informações tanto quanto na compreensão do processo de conhecimento em Antropologia uma vez que permitiu vislumbrar, de forma evidenciada, o sujeito que interpreta. ${ }^{10} \mathrm{~A}$ captação de imagens foi encarada um instrumento de síntese cognitiva de apreensão estética do universo das ruínas em Porto Alegre - tanto do dado inteligível quanto do dado sensível da realidade investigada, portanto, como instrumento de expressão estética e de construção de significados.

Pelo caráter informal e experiência do vídeo-documentário Cidade e suas ruínas, é que optou por denominar as imagens apresentadas sob o nome de notas videográficas, referindo-nos aqui a André Leroi-Gourhan ${ }^{11}$ que elaborou o conceito de "notas

\footnotetext{
${ }^{9}$ A propósito, ver Satt, M.H. Circularidades e Superfícies: leituras videográficas das imagens batuqueiras. Dissertação de Mestrado em Multimeios, UNICAMP, 1995.

${ }^{10}$ Clifford, J. 'Sobre l'autoridad etnográfica', in: El surgimento de la Antropologia posmoderna, Reynoso, C. (org.), Mexico, Gedisa, 1991.

${ }^{11}$ Em 1948, André Leroi-Gourhan escreveu um artigo intitulado "Le film ethnographique existe-t-il?". Nele, o etnólogo afirmava que o filme de pesquisa compreende dois tipos. O primeiro, classificou como "notas cinematográficas", rodadas no dia-a-dia sem planos pré concebidos. O segundo, que chamou de "filme organizado", é produzido sem preocupações comerciais, mas suscetível de interessar o grande público. Cf. HEUSCH, Luc de. Cinéma et sciences sociales: panorama du film ethnographique et sociologique. Paris, 1962. p. 18. Unesco
} 
cinematográficas" ao considerar o personagem do documentarista social que filma fazendo anotações visuais $^{12}$.

Como parte integrante da pesquisa, tais experimentos etnográficos em "territóriosmito" da cidade de Porto Alegre, explorou-se as formas de seus "cenários-tipo", seus "personagens-tipo", suas "situações-tipo' no jogo da tessitura da temporalidade das intrigas que encerram.

Atentos aos 'gêneros confusos' que podem resultar do uso da metáfora teatral para a apreensão da expressão estética que rege as formas de vida coletiva na cidade, tanto quanto o abuso da metáfora do texto para interpretar a ação simbólica que configura a teia de significados da cultura, o que se pretendeu com este vídeo foi essencialmente explorar os múltiplos campos de narrativas que finalmente "armam" a trama da etnografia do e no meio urbano como parte do 'fazer antropológico'.13

\section{A guisa de conclusão}

Partindo, portanto, da observação das "anotações visuais" ( edição de pequenos documentários etnográficos) e das construções narrativas, executadas no trabalho de campo, é que este vídeo, finalmente pode ser visto como parte da intenção que move o Sub-projeto, ou seja, a elaboração e realização da documentários etnográficos, a síntese do processo dessa pesquisa. ${ }^{14}$

Falar da cidade e das formas estéticas que revestem as formas de vida coletiva no meio urbano como objeto de investigação desta pesquisa representa uma preocupação com a pesquisa antropológica a partir do paradigma estético na interpretação das figurações da vida social na Cidade. Trata-se aqui, portanto, de um investimento de pesquisa que

\footnotetext{
${ }^{12}$ A tendência de ir a campo sem um planejamento pré-concebido obteve seguidores. A antropóloga visual Claudine de France, por exemplo, sugere que "o registro cinematográfico, suporte da observação diferida das imagens, torna-se o ato primeiro da pesquisa. O filme abre a investigação". Cf. FRANCE, Claudine. Cinéma et anthropologie. Paris, Editions de La Maison des Sciences de L'Homme, 1982. p. 305 - 309. Contudo, diferentemente da proposta experimental e plural em relação aos procedimentos metodológicos que desenvolvo aqui, sua teoria estabelece normas precisas sobre o que registrar - "técnicas rituais, materiais ou corporais" - e como fazê-lo.

${ }^{13}$ A propósito, ver Geertz, C. 'Gêneros confusos', in: El surgimiento de la Antropologia posmoderna, op.cit.

${ }^{14}$ Tendo em vista que o nosso objetivo é o estudo de técnicas narrativas para a construção de novas propostas de documentários etnográficos da e na cidade, a reflexão e manipulação das imagens é uma constante em nosso processo de trabalho. Portanto, as anotações visuais as quais nos referimos envolvem tanto o momento anterior de reflexão e pesquisa de diferentes propostas narrativas, como o posterior na edição, onde grosso modo, concluímos um recorte, dando forma final ao relato que denominamos notas visuais.
} 
contempla como fonte de investigação a própria retórica analítica do pesquisador em seu diálogo com o seu objeto de pesquisa; a Cidade e seus habitantes.

Tomando-se os artefatos da performance cultural no meio urbano de Porto Alegre como fonte de investigação, o uso de recursos eletrônicos como correspondente analógico das 'anotações de campo' empregada na etnografia realista pode ajudar aqui na reflexão em torno dos limites do 'giro interpretativo' em se trabalhar a cultura como um "texto" das implicações do antropólogo como intérprete de sua teia de significados.

Por outro lado, a 'analogia dramática' da vida social permite, nesta pesquisa, aprofundar-se a perspectiva da poiesis ${ }^{15}$ que rege as formas de se estar-junto nos territórios da Cidade, observando, no estudo do patrimônio etnológico do mundo urbano, os mecanismos expressivos da personalidade ética e do comportamento estético de seus moradores.

Teoria da ação simbólica, e a perspectiva do drama (aqui visto como muthos) ${ }^{16}$ na configuração das tramas da vida urbana conduzem aqui a pensar-se novas possibilidade para a criação de roteiros sobre estética urbana e memória coletiva no mundo urbano contemporâneo.

inspirada nos estudos de narrativas como fonte de pesquisa para documentários etnográficos no e do meio urbano e o lugar do etnógrafo não como interprete do 'nativo' mas como intérprete de si mesmo, do lugar que ocupa no diálogo com o outro ao diálogo que ele oculta consigo mesmo quando constrói o seu texto.

O emprego de registros visuais e sonoros como lugar da construção dos experimentos etnográficos permitiu, finalmente, com este vídeo um estudo mais detalhado do "circulo hermenêutico" que configuradora a tessitura do texto etnográfico.

O que o vídeo tematiza, finalmente, é a possibilidade não apenas do registro, no tempo, do processo de investigação do antropólogo no mundo urbano (seus dilaceramentos na interpretação do ato de destruição como metáfora das indagações sobre a crise nas modernas cidades urbano-industriais, do registro da expressão estética que move o antropólogo 'em situação' de pesquisa de campo, no seio da qual emerge a etnografia como construção de uma inteligência narrativa do investigador.

\footnotetext{
${ }^{15}$ Ricoeur, P. Tempo e Narrativa. Vol I, SP, Papirus, 1994, pp. 55-76.

${ }^{16}$ Ricoeur, R. op,cit, pp. 85-133
} 
Referências

BACHELARD, G. La poétique de l'espace. Paris, Corti, 1989.

CARDOSO DE OLIVEIRA, R. A Sobre o pensamento antropologico.

CLIFFORD, J. Sobre la autoridad etnográfica. In: Reynoso, C. (org.). El surgimento de la antropologia posmoderna. Barcelona, Gedisa, 1991.

CATÁLOGO II Mostra Internacional de Antropologia Visual, Rio de Janeiro, 1994

DURAND, G. Les strutuctures anthropologiques de 1 'imaginaire. Paris, Dunod. 1984.

FRANCE, Claudine. "Pour une anthropologie visuelle". Paris, Cahiers de L'Homme, 1979.

GEERTZ, C. 'Gêneros confusos'. In: Reynoso, C. (org.). El surgimento de la antropologia posmoderna. Barcelona, Gedisa, 1991.

HEUSCH, Luc de. Cinéma et sciences sociales: panorama du film ethnographique et sociologique. Paris, 1962. p. 18. Unesco

MARCUS, E. G.e CUSHMAN, E.D., Las etnografias como textos. in: Reynoso, C. (org). El surgimento de la antropologia posmoderna. Barcelona, Gedisa, 1991.

MENEZES, C. (org.) Antropologia Visual. Caderno de Textos. Rio de Janeiro, Museu do Indio, 1987. Ricoeur, P. Tempo e Narrativa, Vol. I e II. São Paulo, Papirus, 1994.

SIMMEL, G. Cultura femenina y otros ensayos. Madrid, , 1934.

XAVIER, Ismail (org.). A experiência do cinema. Rio de Janeiro, Graal, 1983.

SATT, M.H. Circularidades e Superfícies: leituras videográficas das imagens batuqueiras. Dissertação de Mestrado em Multimeios, UNICAMP, 1995.

LEROI-GOURHAN, A "Le film ethnographique existe-t-il?" In: "Pour une anthropologie visuelle". Paris, Cahiers de L'Homme, 1979. 